\title{
Relationship between Types of Forced Laughter and Mental Health: Mediating Effects of Social Support and Self-Concept Clarity
}

\author{
Ryota Tsukawaki ${ }^{1} \&$ Tomoya Imura ${ }^{2}$ \\ ${ }^{1}$ Department of Social and Clinical Psychology, Hijiyama University, Hiroshima, Japan \\ ${ }^{2}$ Graduate School of Teacher Education, Saga University, Saga, Japan \\ Correspondence: Ryota Tsukawaki, Hijiyama University, 4-1-1 Ushitashinmachi, Higashi-ku, Hiroshima, Japan.
}

Received: December 12, 2019

Accepted: January 6, 2020

Online Published: January 7, 2020

doi:10.5539/ijps.v12n1p1

URL: https://doi.org/10.5539/ijps.v12n1p1

\begin{abstract}
We explored the relationship between four types of forced laughter (expression control, intimacy maintenance, action control, and affect manipulation) and mental health as well as the mediating effects of social support and self-concept clarity. The Forced Laughter Scale (FLS), General Health Questionnaire-12 (GHQ-12), Multidimensional Scale of Perceived Social Support (MPSS), and Self-Concept Clarity Scale (SCC) were completed by 184 (63 male, 119 female) Japanese university students. The results of investigating the relationships between the four types of forced laughter and mental health demonstrated that expression control had a negative correlation with mental health, while intimacy maintenance had a positive correlation. Affect manipulation and action control did not demonstrate significant correlations. Mediation analysis revealed that the negative correlation between expression control and mental health can be explained by a low level of perceived social support and self-concept clarity. Conversely, it was revealed that the positive correlation between intimacy maintenance and mental health can be explained by a high level of perceived social support. This study found that forced laughter in daily life can have both positive and negative correlations with mental health depending on the situation in which one forces a laugh and their intention for doing so.
\end{abstract}

Keywords: forced laughter, social support, self-concept clarity, mental health

\section{Introduction}

\subsection{Humor, Laughter, and Mental Health}

Though the concept of humour is extremely ambiguous, Martin (2007) stated that humour is an 'emotional response of mirth in a social context that is elicited by a perception of playful incongruity' (p. 10). Meanwhile, 'laughter is a psychophysiological response to humour that involves both characteristic physiological reactions and positive psychological shifts' (Bennett \& Lengacher, 2006, p. 62). It has long been believed that humour and laughter are beneficial to mental health and researchers have been advancing empirical research on the various aspects of humour, laughter, and mental health since the 1980s.

Experimental research has revealed that when participants were shown humorous stimuli in the form of images or sounds, negative mood including anxiety, depressed mood, and emotional distress was reduced through humour and laughter (Szabo, 2003; Szabo, Ainsworth, \& Danks, 2005), while positive feelings about life including feelings of hopefulness increased (Vilaythong, Arnau, Rosen, \& Mascaro, 2003). Research using the correlational method conceptualises individual differences in individuals' humour and laughter as their 'sense of humour' and explores the relationship with various mental health indexes. Sense of humour scales can assess humour and laughter occurring in an individual's daily life and in various social contexts. A multitude of humour scales have been developed in the past, but the Humour Styles Questionnaire (HSQ) developed by Martin, Puhlik-Doris, Larsen, Gray, and Weir (2003) is an effective scale that has been frequently used in recent years. The HSQ assesses the individual differences in individuals' humour and laughter on four subscales: Affiliative Humour, Self-Enhancing Humour, Aggressive Humour, and Self-Defeating Humour. Affiliative Humour assesses trends in the use of humour or laughter for the enjoyment of others or deepening relationships. Self-Enhancing Humour assesses trends in coping with stress through humour or laughter. Aggressive Humour assesses trends in the use of humour or laughter to criticise or dominate others. Lastly, Self-Defeating Humour assesses trends in the use of humour or laughter in a self-sacrificing manner to gain someone's favour. According to research using 
the HSQ, Affiliative Humour and Self-Enhancing Humour are beneficial to mental health, while Aggressive Humour and Self-Defeating Humour are negative (Kuiper, Grimshaw, Leite, \& Kirsh, 2004; Martin et al., 2003).

By grasping humour and laughter in the social context using the HSQ, it is possible to hypothesise several types of humour and laughter. Types that are beneficial to mental health, as well as those that are harmful, have been discovered.

\subsection{Separating the Effects of Humour and Laughter on Mental Health}

By nature, the effects of humour and laughter are separate phenomena that should be investigated individually (Bennett \& Lengacher, 2006). Humans can express laughter even without feeling humour and the opposite is also possible. However, much of the past research does not handle the two concepts individually. In the majority of research using the experimental method, the design involves presenting the participant with a humorous stimulus. With this method, the participants are feeling humour and simultaneously laughing in response. Therefore, it is difficult to separate the two parameters. Likewise, in correlational research using scales, it is impossible to specify whether the correlation with indexes of mental health is reflecting individual differences due to humour or due to laughter. One method to resolve this problem is to advance research regarding forced laughter. Forced laughter is 'laughter on the outside only that is not due to a natural emotion such as amusement or joy' (Oshimi, 2002, p. 252). We define forced laughter as laughter not accompanied by humour. By investigating the relationship between forced laughter and mental health it is possible to explore the effects of laughter separate from humour.

There have already been several studies that experimentally explored the effects of forced laughter. Strack, Martin, and Stepper (1988) found that participants who were instructed to rate the funniness of a comic while holding a pen in their mouth so as to contract the facial muscles related to laughter, rated the comic as funnier than participants who held the pen in their mouth so as not to contract those muscles. These participants also experienced an improvement in positive mood. Further, it has been reported that a group of participants who carried out a session of forced laughter without a humorous stimulus had significantly better positive mood than the baseline or control groups (Foley, Matheis, \& Schaefer, 2002; Neuhoff \& Schaefer, 2002).

However, it has been reported that humans force laughter for various reasons in the social contexts of daily life (Ekman \& Friesen, 1975). As demonstrated by recent research on sense of humour, even for forced laughter, it is anticipated that its relationship with mental health differs depending on the situation and intention with which it is done. Nonetheless, previous research has not investigated this point.

\subsection{Types of Forced Laughter}

Ekman and Friesen (1975) noted that humans attempt to influence others through control of the facial expressions that represent their emotions; the researchers also noted that laughter and smiles play an essential role among these controlled facial expressions. According to Ekman and Friesen, people often laugh as a comment on their own emotional expression. Intentionally smiling after making an angry facial expression is an attempt to express supplementary information that their anger is not so intense. Smiling after evidently (from facial expression) experiencing fear or sadness implies, for others, that one can endure that fear or sadness. Further, laughter and smiles can be used to conceal or disguise one's true emotions. Making a facial expression that seems to imply one is feeling a specific emotion, despite presently feeling no emotion at all, is called simulating; for example, one may feign laughter even if they do not feel amused. Displaying a facial expression of an emotion one is not feeling in order to conceal what one is actually feeling is called masking. For example, one may show a smile so that others do not perceive emotions of sadness or fear. It is possible to consider the various types of forced laughter by understanding it in the social context.

Oshimi (2002) developed the Forced Laughter Scale (FLS), which categorises and measures an individual's forced laughter in daily life, wherein four types were identified: expression control, intimacy maintenance, action control, and affect manipulation. Expression control is a forced laugh in which one forces oneself to conceal or falsify negative emotions so that others do not perceive these emotions occurring in an interpersonal relationship. An evasive intent lies behind expression control; the individual may be attempting to avoid conflict with others or alienation from a group. Action control is a forced laugh used to regulate or control the actions of others. Its use is accompanied by intent to influence or manipulate others. Intimacy maintenance is a forced laugh used to brighten the atmosphere in a situation or to maintain or improve one's level of intimacy with another. Affect manipulation is a forced laugh used to transform negative emotions such as anxiety in oneself or the other party into positive emotion. These two latter types of forced laughter are used to connect with others and form or strengthen interpersonal relationships. Although the FLS was developed in a study clarifying characteristics of individuals with high public self-consciousness and its relationship with mental health has not been explored, it 
is possible to explore the relationship between various types of forced laughter and mental health through the use of this scale.

\subsection{Mediators in the Relationship between Forced Laughter and Mental Health}

Existing literature (Foley et al., 2002; Neuhoff \& Schaefer, 2002: Strack et al., 1988) consistently reports the positive effects of forced laughter, but when we focus on forced laughter in the social context, all types do not seem to have a positive effect; it is anticipated that some types will have a negative effect. It is thought that intimacy maintenance and affect manipulation are useful in the maintenance and development of smooth social relationships (Oshimi, 2002). These types involve intentions such as encouraging others when they are feeling sad or alleviating uncomfortable emotions in the self or others, and it is expected that they are useful in improving the quality of social relationships. On the other hand, it is expected that expression control and action control will not have the effect of improving the quality of social relationships; rather, it is thought that action control may worsen the quality of social relationships if the control fails. There is extensive and consistent literature demonstrating that social support, which reflects the quality of an individual's social relationships, is related to mental health (Uchino, Bowen, Carlisle, \& Birmingham, 2012). Accordingly, it is conceivable that intimacy maintenance and affect manipulation mediate high levels of social support and thereby have a positive effect on mental health, while action control mediates low levels of social support and thereby has a negative effect.

Further, expression control is the act of concealing one's actual emotions or falsifying expression. In other words, it is emotional suppression. While other types of forced laughter also include emotional suppression, expression control is more strongly involved in emotional suppression than other types as it consists of forcibly suppressing negative emotions. Berry and Pennebaker (1993) identified that individuals who regulate negative emotions and do not express them are more mentally and physically unhealthy than those who do the opposite. Gross and John (2003) suggested that one reason for deterioration of mental health among individuals who suppress emotions may be a conscious sense that the self is not acting authentically or in a way consistent with one's actual feelings. When individuals suppress emotions, they may consciously perceive that their internal emotions and external behavior are not consistent (Higgins, 1987). Choi and Arai (1997) stated that if one always conceals and suppresses their own emotions to go along with others, they may lose their identity. In other words, concealing the true self through expression control is thought to degrade their self-concept clarity and harm their mental health.

Self-concept clarity is an idea representing 'the extent to which the contents of an individual's self-concept are clearly and confidently defined, internally consistent, and temporally stable' (Campbell, Trapnell, Heine, Katz, Lavallee, \& Lehman, 1996, p. 141). Both longitudinal studies (Lee-Flynn, Pomaki, DeLongis, Biesanz, \& Puterman, 2011) and experimental studies (Stucke \& Sporer, 2002) have demonstrated that self-concept clarity has an impact on mental health, and that low self-concept clarity may be linked to negative emotions and depressive symptoms. Therefore, expression control mediates a reduction in self-concept clarity and is thought to have a negative effect on mental health.

\subsection{The Objectives and Hypotheses of the Present Study}

Accordingly, our goal was to explore the relationship between types of forced laughter and mental health, as well as the mediating effects on this relationship from social support and self-concept clarity. Our first hypothesis was that intimacy maintenance and affect manipulation would be positively correlated with mental health, while expression control and action control would be negatively correlated with mental health. Our second hypothesis was that the relationship between intimacy maintenance, affect manipulation, action control, and mental health would be mediated by social support, while the relationship between expression control and psychological health would be mediated by self-concept clarity.

\section{Method}

\subsection{Participants and Procedure}

The survey was implemented with students majoring in psychology at a private university in Hiroshima Prefecture, Japan, in their free time after classes were over. An explanation of informed consent was provided in advance and 203 consenting Japanese university students participated in the survey. A self-administered survey was distributed among the groups of participants, which they took 20 minutes to complete. Data including missing values were excluded and the final sample was composed of 182 individuals (63 males, 119 females). The average age was 19.10 years $(\mathrm{SD}=1.78$ years $)$. 


\subsection{Measures}

\subsubsection{Forced Laughter}

We used the Forced Laughter Scale (FLS; Oshimi, 2002). The FLS is a scale with 20 items and four subscales: Expression Control ('When a friend is laughing, I pretend to laugh even if it isn't funny'); Intimacy Maintenance ('In order to brighten the atmosphere of the place, I intentionally laugh a lot'); Action Control ('I make fun of a different group and then laugh on purpose with my friends') and Affect Manipulation ('When another person looks to be in a bad mood, I purposely meet them with a smile'). Respondents assessed each item on a 5-point Likert scale $(1=I$ don't do this at all to $5=I$ do this very often $)$ for the degree of applicability to themselves. Internal consistency (Cronbach's $\alpha$ ) in this study was 0.71 for Expression Control, 0.78 for Intimacy Maintenance, 0.72 for Action Control, and 0.63 for Affect Manipulation. A higher score denotes higher use of that type of forced laughter in daily life.

\subsubsection{Mental Health}

The Japanese version (Niiro \& Mori, 2001) of the General Health Questionnaire-12 (GHQ-12; Goldberg \& Williams, 1988) was used. The GHQ-12 is composed of 12 items that are used to assess one's recent mental health status on a 4-point Likert scale. The response options for the GHQ-12 vary by item. For example, for the question 'Have you felt more unhappy or depressed than usual recently?' respondents choose from 1 (Not at all) to 4 (Frequently), while for the question 'Have you been easily able to make decisions about things?' respondents choose from 1 (I have been able to) to 4 (I haven't been able to at all). Though there are several scoring methods for the GHQ-12, we used the Likert method (all items coded 1-2-3-4). The internal consistency for this study was 0.86 . A higher score denotes a higher level of mental health.

\subsubsection{Social Support}

The Japanese version (Iwasa et al., 2007) of the Multidimensional Scale of Perceived Social Support (MPSS; Zimet, Dahlem, Zimet, \& Farley, 1988) was used. The MPSS is a 12-item scale composed of three subscales: Support from Family (e.g. 'I can talk with my family about problems between us'), Support from Significant Other (e.g. 'I have someone who can share in my joys and sorrows'), and Support from Friends (e.g. 'My friends really try to help me out'). Respondents assess the degree of applicability to themselves on a 7-point Likert scale $(1=I$ don't think so at all to $7=I$ definitely think so $)$. In this study, the total score for social support was calculated from the total score on each of the three subscales. The internal consistency for the MPSS in this study was 0.93 . A higher score denotes a higher level of perceived social support.

\subsubsection{Self-Concept Clarity}

The Japanese version (Tokunaga \& Horiuchi, 2012) of the Self-Concept Clarity Scale (SCC; Campbell et al., 1996) was used. The SCC is a 12-item scale (e.g. 'I rarely feel there are inconsistencies between the various aspects of my personality') and respondents assess items on a 5-point Likert scale $(1=$ Strongly disagree to $5=$ Strongly agree). Internal consistency for this study was 0.75. A higher score denotes a higher level of self-concept clarity.

\subsection{Statistical Analysis}

First, descriptive and bivariate analyses were conducted for our main study variables. Next, a multiple regression analysis was used to determine the effects of the explanatory variable (type of forced laughter) on the dependent variable (mental health). For laughter types that demonstrated a significant direct effect, we then tested for mediating effects from social support and self-concept clarity.

We conducted multiple mediation analyses with social support and self-concept clarity as mediators by Process Macro for SPSS (Hayes, 2013). At this time, we controlled for the three types of forced laughter that were not the target of analysis. For example, when examining the mediating effects in the relation between expression control and mental health, intimacy maintenance, action control, and affect manipulation were controlled. According to Preacher and Hayes (2008), testing for the significance of indirect effects was done using the bootstrapping method. The bootstrap method used 5000 samples. Indirect effects were deemed significant if the $95 \%$ confidence intervals did not include zero.

\section{Results}

\subsection{The Relationship between Types of Forced Laughter and Mental Health}

Means, standard deviations, and intercorrelations among study variables are presented in Table 1. The relationship between the explanatory variable (type of forced laughter) and dependent variable (mental health) was investigated using a multiple regression analysis. As a result, expression control demonstrated a significant 
negative effect on mental health $(\beta=-.52, p<.01)$, while intimacy maintenance demonstrated a significant positive effect $(\beta=.18, p<.05)$. Meanwhile, action control and affect manipulation did not demonstrate significant effects $(\beta \mathrm{s}=.09$ and .07 , both $n s)$. As such, we next examined the mediating effects of social support and self-concept clarity, with expression control and intimacy maintenance as the independent variables and mental health as the dependent variable.

Table 1. Means, standard deviations, and intercorrelations among study variables

\begin{tabular}{cccccccc}
\hline & 1. & 2. & 3. & 4. & 5. & 6. & 7. \\
\hline 1. Expression control & - & $.57^{* *}$ & $.28^{* *}$ & $.36^{* *}$ & $-.37^{* *}$ & -.04 & $-.42^{* *}$ \\
2. Intimacy maintenance & & - & $.24^{* *}$ & $.47^{* *}$ & -.06 & $.33^{* *}$ & $-.26^{* *}$ \\
3. Action control & & & - & $.43^{* *}$ & .02 & .08 & $-.18^{*}$ \\
4. Affect manipulation & & & & - & .01 & $.18^{*}$ & $-.26^{* *}$ \\
5. Mental health & & & & & - & $.39^{* *}$ & $.45^{* *}$ \\
6. Social support & & & & & & - & .07 \\
7. Self-concept clarity & & & & & & & - \\
$M$ & 3.21 & 3.51 & 2.57 & 2.82 & 2.68 & 5.23 & 2.89 \\
$S D$ & 0.72 & 0.66 & 0.75 & 0.78 & 0.50 & 1.16 & 0.53 \\
\hline
\end{tabular}

$* p<.05 \quad * * p<.01$

\subsection{Expression Control}

We began by testing for mediating effects from social support and self-concept clarity in the relationship between expression control and mental health (Table 2). On tests for a significant indirect effect of social support and self-concept clarity, the $95 \%$ CI did not include zero, suggesting that both are significant. Additionally, the direct effect of expression control on mental health remained significant even when a mediating variable was introduced. This suggests that social support and self-concept clarity demonstrate partial mediation in this relationship. In addition, the value of variance influence factor (VIF) was less than 1.22 , even in the regression formula, which included the mediating variable along with expression control as an independent variable. Therefore, we concluded that multicollinearity was not a concern in the current analyses.

Table 2. Mediating effects in the relationship between expression control and mental health

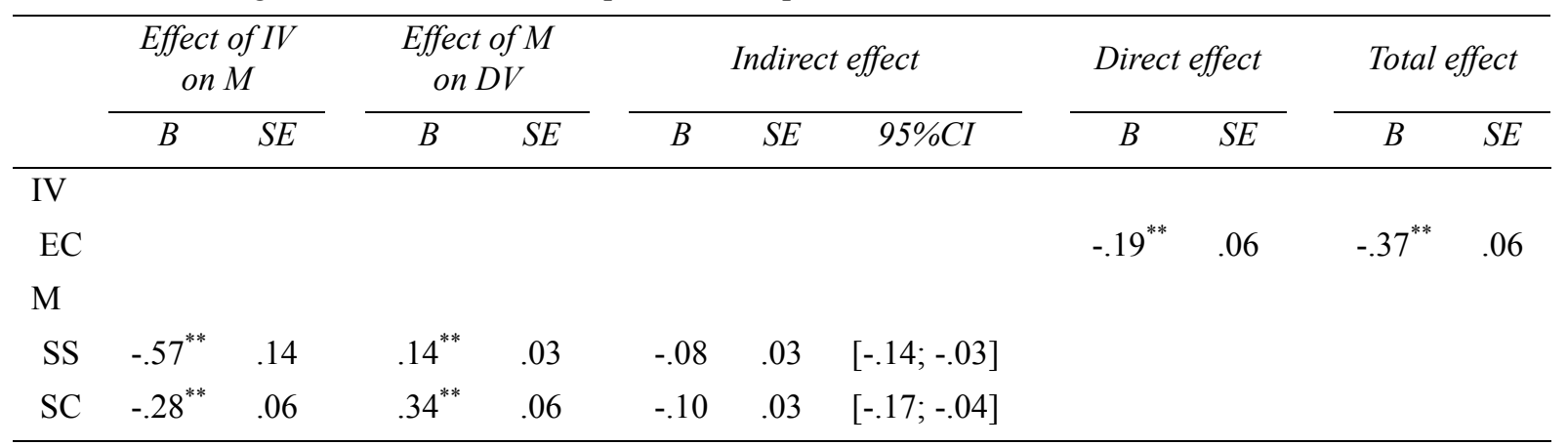

Note. Non-standardized beta coefficients are provided. IV, independent variable; M, mediator; DV, dependent variable; EC, expression control; SS, social support; SC, self-concept clarity.

$* * p<.01$

\subsection{Intimacy Maintenance}

We then tested for mediating effects from social support and self-concept clarity in the relationship between intimacy maintenance and mental health (Table 3). On tests for a significant indirect effect of social support, the $95 \% \mathrm{CI}$ did not include zero, suggesting that social support is significant; however, as the $95 \% \mathrm{CI}$ for the test of 
self-concept clarity did include zero, it was not deemed significant. Additionally, the direct effect of intimacy maintenance on mental health was not found to be significant. This suggests that social support demonstrates complete mediation in this relationship. In addition, the value of VIF was less than 1.23 , even in the regression formula which included the mediating variable along with intimacy maintenance as an independent variable. Therefore, we concluded that multicollinearity was not a concern.

Table 3. Mediating effects in the relationship between intimacy maintenance and mental health

\begin{tabular}{|c|c|c|c|c|c|c|c|c|c|c|c|}
\hline & \multicolumn{2}{|c|}{$\begin{array}{l}\text { Effect of IV } \\
\text { on } M\end{array}$} & \multicolumn{2}{|c|}{$\begin{array}{c}\text { Effect of } M \\
\text { on } D V\end{array}$} & \multicolumn{3}{|c|}{ Indirect effect } & \multicolumn{2}{|c|}{ Direct effect } & \multicolumn{2}{|c|}{ Total effect } \\
\hline & $B$ & $S E$ & $B$ & $S E$ & $B$ & $S E$ & $95 \% C I$ & $B$ & $S E$ & $B$ & $S E$ \\
\hline \multicolumn{12}{|l|}{ IV } \\
\hline IM & & & & & & & & .01 & .06 & $.14^{*}$ & .07 \\
\hline \multicolumn{12}{|l|}{ M } \\
\hline SS & $.88^{* *}$ & .15 & $.14^{* *}$ & .03 & .12 & .04 & {$[.05 ; .20]$} & & & & \\
\hline $\mathrm{SC}$ & .01 & .07 & $.34^{* *}$ & .06 & .00 & .03 & {$[-.05 ; .06]$} & & & & \\
\hline
\end{tabular}

Note. Non-standardized beta coefficients are provided. IV, independent variable; M, mediator; DV, dependent variable; IM, intimacy maintenance; SS, social support; SCC, self-concept clarity.

$* * p<.01 \quad * p<.05$

\section{Discussion}

This study is the first to explore the relationship between the four types of forced laughter (expression control, intimacy maintenance, action control, and affect manipulation) using the FLS and mental health. This study also explored the mediating effects of social support and self-concept clarity on the relationship between forced laughter and mental health.

First, when the association between the four types of forced laughter and mental health were investigated using multiple regression analysis, expression control was found to be a significant negative predictor, and the maintenance of intimacy was a significant positive predictor, consistent with our predictions. However, affect manipulation and action control were not found to be significant predictors of mental health, suggesting that the of use of these types of forced laughter was not related to mental health. The results regarding the relationship between the four types of forced laughter and mental health obtained in this study showed that not all types of forced laughter in social interactions are related to mental health, and that the way they are related is not uniform. Research experimentally exploring the relationship between forced laughter and mental health has consistently reported a positive effect (Foley et al., 2002; Neuhoff \& Schaefer, 2002; Strack et al., 1988). Therefore, the fact that this study demonstrated the possibility that there is no relationship with mental health depending on the type of forced laughter, and further that some types may conversely have a negative effect is a major result.

The results of the mediation analysis showed that the relationship between expression control and mental health was partially mediated by self-concept clarity. This result supported our prediction that concealing one's true self through expression control destabilises one's belief regarding their self-concept and, as a result, mental health is damaged. However, beyond our prediction, it was demonstrated that the relationship between expression control and mental health was also partially mediated by social support. In other words, it suggests that expression control may reduce mental health by damaging the quality of social relationships. The possibility that attempts at concealing one's negative emotions through expression control in daily life are not very successful should be considered. Soppe (1988) experimentally revealed that both children and adults are able to detect when someone else is concealing or suppressing a negative emotion. From this, we can interpret that expression control results in giving one's interaction partner an uncomfortable impression and reduces the quality of social relationships. However, we need to be aware that these mediation effects are partial. It is necessary for researchers to pursue further routes in the relationship between expression control and mental health.

As we predicted, the relationship between intimacy maintenance and mental health was completely mediated by social support. It was demonstrated that forced laughter for intimacy maintenance- to improve the mood in a situation or to improve one's level of intimacy with others - works to improve the quality of social relationships. Recent research also demonstrated that the relationship between an individual's use of humour in daily life and 
mental health and life satisfaction was mediated by social support (Dyck \& Holtzman, 2013). As most humour and laughter are social phenomena experienced in interactions with others (Provine \& Fischer, 1989), it is possible that many of these psychological effects, including those of forced laughter, are mediated through the quality of social relationships.

Lastly, we discuss the limitations of this study and prospects for future research. One major limitation of our research is the cross-sectional design. Consequently, we cannot draw clear conclusions regarding the causal direction in the relationships between the variables. Based on our knowledge of the experimental research regarding forced laughter and mental health (Foley et al., 2002; Neuhoff \& Schaefer, 2002; Strack et al., 1988), we have assumed a causal direction in which forced laughter has an effect on mental health. However, in the field of neurology, Duchowny (1983) pointed out that patients with mental illnesses (e.g. schizophrenia, mania) are emotionally unstable and sometimes cannot control their laughter. As such, the opposite causal direction, in which forced laughter is influenced by one's mental health status, is also possible. Future studies are needed that demonstrate evidence of the influence the types of forced laughter have on mental health through experimental research or studies using a longitudinal design. Further, there is a standard limitation to the generalisation of these results, as our sample consisted of Japanese university students. In the future, it is necessary to explore whether the same results are demonstrated in different age groups, ethnic groups, and countries.

Overall, the study demonstrated that the type of forced laughter used in a strained attempt to suppress negative emotions in interpersonal relationships (expression control) results in decreased self-concept clarity. Furthermore, by adversely affecting the quality of relationships with surrounding individuals, it also has a negative influence on mental health. Conversely, the type of forced laughter intended to brighten and enliven a given situation (intimacy maintenance) improves the quality of relationships one has with surrounding individuals and seems to have a positive influence on mental health. Therefore, the effect of forced laughter on mental health appears to differ depending on the way it is used within a given social context. While existing intervention studies making use of forced laughter have reported a positive impact on mental health (Foley et al., 2002), we feel that in cases where research participants are asked to apply forced laughter to daily interactions, caution should be urged in regard to the use of expression control.

\section{Declaration of Conflicting Interests}

The author(s) declare no potential conflicts of interest with respect to the research, authorship, and/or publication of this article.

\section{References}

Bennett, M. P. \& Lengacher, C. A. (2006). Humor and laughter may influence health. I: History and background. Evidence-Based Complementary and Alternative Medicine, 3, 61-63. http://dx.doi.org/10.1093/ecam/nek015

Berry, D. S. \& Pennebaker, J. W. (1993). Nonverbal and verbal emotional expression and health. Psychotherapy and Psychosomatics, 59, 11-19. http://dx.doi.org/10.1159/000288640

Campbell, J. D., Trapnell, P. D., Heine, S. J., Katz, I. M., Lavallee, L. F. \& Lehman, D. R. (1996). Self-concept clarity: Measurement, personality correlates, and cultural boundaries. Journal of Personality and Social Psychology, 70, 141-156. http://dx.doi.org/10.1037/0022-3514.70.1.141

Choi, K. \& Arai, K. (1997). A brief review of the studies on 'emotional expression and regulation'. Tsukuba Psychological Research, 19, 29-35. Retrieved from https://tsukuba.repo.nii.ac.jp/

Dyck, K. T. H. \& Holtzman, S. (2013). Understanding humor styles and well-being: The importance of social relationships and gender. Personality and Individual Differences, 55, 53-58. https://doi.org/10.1016/j.paid.2013.01.023

Ekman, P. \& Friesen, W. V. (1975). Unmasking the face. New Jersey: Prentice-Hall.

Foley, E., Matheis, R. \& Schaefer, C. (2002). Effect of forced laughter on mood. Psychological Reports, 90, 184. https://doi.org/10.2466/pr0.2002.90.1.184

Goldberg, D. \& Williams, P. (1988). A user's guide to the General Health Questionnaire. Windsor, UK: NFER-Nelson.

Gross, J. J. \&amp; John, O. P. (2003). Individual differences in two emotion regulation processes: Implications for affect, relationships, and well-being. Journal of Personality and Social Psychology, 85, 348-362. https://doi.org/10.1037/0022-3514.85.2.348 
Hayes, A. F. (2013). Introduction to mediation, moderation, and conditional process analysis: A regression-based approach. New York: Guilford Press.

Higgins, E. T. (1987). Self-discrepancy: A theory relating self and affect. Psychological Review, 94, 319-340. http://dx.doi.org/10.1037/0033-295X.94.3.319

Iwasa, H., Gondo, Y., Masui, Y., Inagaki, H., Kawai, C., Otsuka, R. \& Suzuki, T. (2007). Nihongoban 'sosharusapoto shakudo' no shinraisei narabini datosei: Chukonensha wo taisho to shita kento. [Reliability and validity of the Multidimensional Scale of Perceived Social Support Japanese version: A study of middle-aged and elderly]. Journal of Health and Welfare Statistics, 54, 26-33. Retrieved from https://www.hws-kyokai.or.jp/publishing/type/magazine.html

Kuiper, N. A., Grimshaw, M., Leite, C. \& Kirsh, G. A. (2004). Humor is not always the best medicine: Specific components of sense of humor and psychological well-being. Humor: International Journal of Humor Research, 17, 135-168. http://dx.doi.org/10.1515/humr.2004.002

Lee-Flynn, S. C., Pomaki, G., DeLongis, A., Biesanz, J. C. \& Puterman, E. (2011). Daily cognitive appraisals, daily affect, and long-term depressive symptoms: the role of self-esteem and self-concept clarity in the stress process. Personality and Social Psychological Bulletin, 37, 255-268. https://doi.org/10.1177/0146167210394204

Martin, R. A. (2007). The psychology of humor: An integrative approach. New York: Elsevier Academic Press.

Martin, R. A., Puhlik-Doris, P., Larsen, G., Gray. J. \& Weir, K. (2003). Individual differences in uses of humor and their relation to psychological well-being: Development of the Humor Styles Questionnaire. Journal of Research in Personality, 37, 48-75. https://doi.org/10.1016/S0092-6566(02)00534-2

Neuhoff, C. C. \& Schaefer, C. (2002). Effects of laughing, smiling, and howling on mood. Psychological Reports, 91, 1079-1080. https://doi.org/10.2466/pr0.2002.91.3f.1079

Duchowny, M. S. (1983). Pathological disorders of laughter. In P. E. McGhee \& J. H. Goldstein (Eds.), Handbook of humor research, vol. 2: Applied studies (pp. 89-108). New York: Springer-Verlag.

Niiro, M. \& Mori, T. (2001). A study of the reliability and validity of the General Health Questionnaire 12-item Japanese version (GHQ-12) based on corporate employees. Clinical Psychiatry, 43, 431-436. Retrieved from http://www.igaku-shoin.co.jp/top.do

Oshimi, T. (2002). The effect of public self-consciousness on forced laughter. The Japanese Journal of psychology, 73, 251-257. https://doi.org/10.4992/jjpsy.73.251

Preacher, K. J. \& Hayes, A. F. (2008). Asymptotic and resampling strategies for assessing and comparing indirect effects in multiple mediator models. Behavior Research Methods, 40, 879-891. http://dx.doi.org/10.3758/BRM.40.3.879

Provine, R. R. \& Fischer, K. R. (1989). Laughing, smiling, and talking: Relation to sleeping and social context in humans. Ethology, 83, 295-305. https://doi.org/10.1111/j.1439-0310.1989.tb00536.x

Soppe, H. J. G. (1988). Age differences in the decoding of affect authenticity and intensity. Journal of Nonverbal Behavior, 12, 107-119. http://dx.doi.org/10.1007/BF00986929

Strack, F., Martin, L. L. \& Stepper, S. (1988). Inhibiting and facilitating conditions of the human smile: A nonobtrusive test of the facial feedback hypothesis. Journal of Personality and Social Psychology, 54, 768-777. https://psycnet.apa.org/doiLanding?doi=10.1037\%2F0022-3514.54.5.768

Stucke, T. S. \& Sporer, S. L. (2002). When a grandiose image is threatened: Narcissism and self-concept clarity as predictors of negative emotions and aggression following ego-threat. Journal of Personality, 70, 509-532. https://doi.org/10.1111/1467-6494.05015

Szabo, A. (2003). The acute effects of humor and exercise on mood and anxiety. Journal of Leisure Research, 35, 152-162. http://dx.doi.org/10.1080/00222216.2003.11949988

Szabo, A., Ainsworth, S. E. \& Danks, P. K. (2005). Experimental comparison of the psychological benefits of aerobic exercise, humor, and music. Humor: International Journal of Humor Research, 18, 235-246. http://dx.doi.org/10.1515/humr.2005.18.3.235

Tokunaga, Y. \& Takahashi, H. (2012). Development of Japanese version of the Self-concept Clarity (SCC) Scale. The Japanese Journal of Personality, 20, 193-203. https://doi.org/10.2132/personality.20.193 
Uchino, B. N., Bowen, K., Carlisle, M. \& Birmingham, W. (2012). Psychological pathways linking social support to health outcomes: a visit with the 'ghosts' of research past, present, and future. Social Science and Medicine, 74, 949-957. http://dx.doi.org/10.1016/j.socscimed.2011.11.023

Vilaythong, A. P., Arnau, R. C., Rosen, D. H. \& Mascaro, N. (2003). Humor and hope: Can humor increase hope? Humor: International Journal of Humor Research, 16, 79-89. https://doi.org/10.1515/humr.2003.006

Zimet, G. D., Dahlem, N. W., Zimet, S. G. \& Farley, G. K. (1988). The Multidimensional Scale of Perceived Social Support. Journal of Personality Assessment, 52, 30-41. http://dx.doi.org/10.1207/s15327752jpa5201_2

\section{Copyrights}

Copyright for this article is retained by the author(s), with first publication rights granted to the journal.

This is an open-access article distributed under the terms and conditions of the Creative Commons Attribution license (http://creativecommons.org/licenses/by/4.0/). 